\title{
Study on Long-Term Nursing Insurance System
}

\author{
Shiyun Zhang \\ School of Law, Humanities and Sociology \\ Wuhan University of Technology \\ Wuhan, China
}

\author{
Shuai Liu \\ School of Law, Humanities and Sociology \\ Wuhan University of Technology \\ Wuhan, China
}

\author{
Yingying Zhang \\ School of Law, Humanities and Sociology \\ Wuhan University of Technology \\ Wuhan, China
}

\begin{abstract}
The increasingly aging population in Japan since 1990s had been a major social building up burdens and hampering socioeconomic development. Facing with a multitude of senior citizens, handling with aging population tops first on Japanese government's agenda. Among all coping strategies, the Long-term Nursing Insurance System was put forward in 1997. By altering policy entity from central government alone to later including in local authorities and resources from all walks of life, it greatly improved the caring situation and well-being of the aged, and is a leading model of probable solutions to aging society, not least for countries hounded by growing burdens of social welfare. This paper aims to present a brief introduction of this system and an overall analysis of its strengths as well as its improvement since first promulgated.
\end{abstract}

Keywords-aging population; long-term nursing insurance; japan; elderly caring

\section{INTRODUCTION}

The aging society has long been a problematic issue in Japan society since 1990 s, and the aging process is still accelerating. The development of health care and the standard of living due to technological progress has pushed the domestic fertility and morality rate downwards and life expectancy upwards; fertility rate was lower than 2.0 in 1960 and continued decrease to 1.75 in 1995 while life expectancy increased from 71.95 in 1970 to 78.837 in 1990, meaning a growing proportion of old people and a huge demand for targeted care and support. That said, traditional method of elderly-caring was gradually incapable of shouldering the obligation of taking care of the aged. The continuing industrialization speeds up the mobility of population by drawing more young people away from their home and their aging parents and/or relatives requiring attention and care. The family of old solitary people account for $4.8 \%$ in 1975 , $1.5 \%$ higher than 5 years before. All those indicate that traditional family-based pension scheme was out of work, senior care cannot be undertaken by households alone, given the deteriorating aging situation, and government has to step in to improve it.

\section{PRELIMINARY EXPLORATION}

In fact, Japan has long begun to explore possible solutions to senior care. The Welfare Law for the Elderly promulgated in the 1960 s initially established the government's role in providing care for the elderly. The Health Care Law for the Elderly promulgated in the 1980s began to establish some health care facilities that can provide medical care and living assistance, in order to relieve some burden of the households. In 1989, the government enacted the Decade Strategy to Promote Health and Welfare of the Elderly (commonly known as the 'Golden Plan'), which aimed at building more short-term care and daily-care centers in various cities, towns, and villages across the country to make such facilities more accessible. Setting requirements for the number of nurses and the capacity of care-centers, Japanese government carried out active actions to the pressure of the aging society. In 1994, the government formulated the 'New Golden Plan' and continued to increase the number of care-givers and institutions. However, the aging of Japan's population is too fast that the 'New Gold Plan' has been unable to meet the social care demand caused by the rapid aging population. In order to meet the huge demand of nursing care for the elderly, in 1997, the Japanese government adopted the German practice to formulate The Nursing Insurance Law, which was officially implemented in April 2000.

\section{LONG-TERM CARE INSURANCE SYSTEM}

The long-term care insurance system is to integrate the elderly-care into the social public security, by making use of available resources among the society and establishing a pension service system in which all walks of the society collaborate together.

From the perspective of the insured, senior people covered by this program can be divided into two categories. The first type of the insured is 65 years old or above, and the second type is between 40 to 64 years old. When people aged 65 or above need care or support for any reason, and when people aged 40-64 suffer from aging-related diseases 
such as advanced cancer and rheumatoid arthritis, in either case, they can receive long-term nursery insurance service.

\section{A. The Insured}

From the perspective of the insured, senior people covered by this program fall into two categories. The first type of the insured is 65 years old or above, and the second type is between 40 to 64 years old. When people aged 65 or above need care or support for any reason, and when people aged 40-64 suffer from aging-related diseases such as advanced cancer and rheumatoid arthritis, in either case, they can receive long-term nursery insurance service.

\section{B. Financing}

In terms of financing, the premiums for long-term care insurance consist of two major parts, equally shared by the government and the individuals. The fare paid by the government comes from three sources. The city and townships bear $12.5 \%$ of the total premiums, the prefectures and counties another $12.5 \%$, and the state pays the rest $25 \%$. By well-combining the national and personal contributions, the insurance premiums are equally shared. Such method improves the earlier situation that the burden is solely laid on the country and further shifted to the high and middle income earners. In order to prevent the abuse of insurance premiums and nursing services, the Japanese government also stipulates that long-term care insurance pays only $90 \%(80 \%)$ of the cost of nursing services, and the remaining $10 \%(20 \%)$ is paid in principle by the insured themselves. In addition, individuals must also pay for additional actual accommodation and dining cost.

\section{Structure of the Long-Term Care Insurance System}

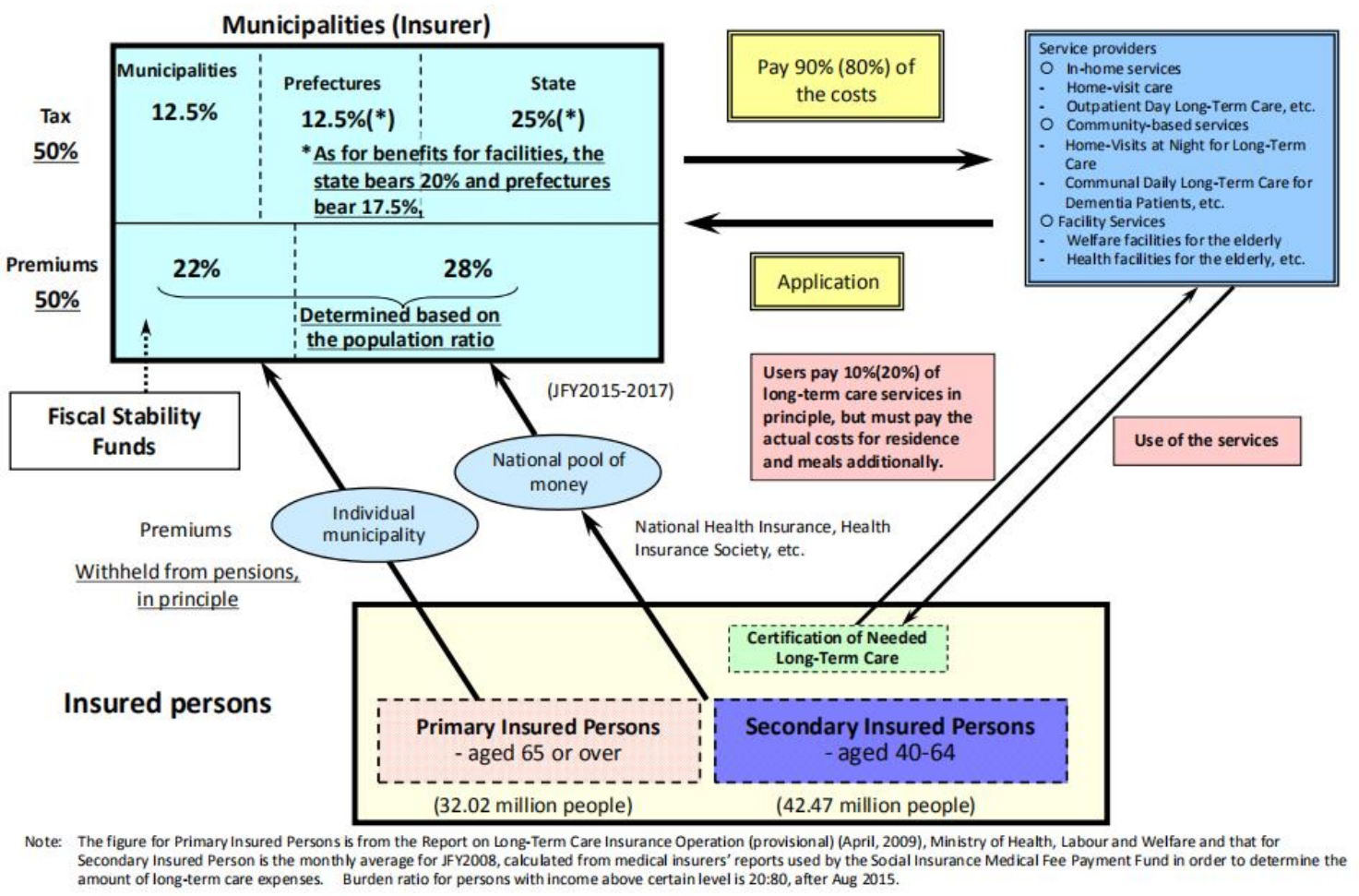

Fig. 1. Structure of the Long-term Insurance System.

\section{Administrative System}

Taking a look at the administrative system, the Ministry of Health and Welfare is the planner of the long-term care insurance system. Each municipality is a statutory insurer, responsible for the collection and management of premiums and the deployment home care services. This shows that the long-term care insurance service is carried out in the city, town and village where the elderly are located. The city, townships and villages continue to play their important role inherited from the 'golden planning period' in home-based care for seniors, further increasing the accessibility of homebased care services.

\section{Service}

Speaking of the service, there are many types of longterm care insurance services. It can be divided into five major categories, namely home visit service, day service, short stay service, residential service and in-facility service. Specifically, it includes 14 home care services and 3 infacility services. 14 home care services include home-visit services, outpatient home care, short-term in-facility daily 
care, and housing renovation financial support. In-facility services are divided into, depending on physical condition of the elderly, in-facility services, day health care facilities and day care in-facility rehabilitation.

\section{E. Operational Process}

From the perspective of the operational process, the insured who need nursing services first need to apply from the competent department of the municipality where they are located. After that, the municipality will send investigators to visit the elderly's family, and conduct an evaluation of the physical condition of the elderly by examining a number of indicators, combining the opinions of the attending physician.

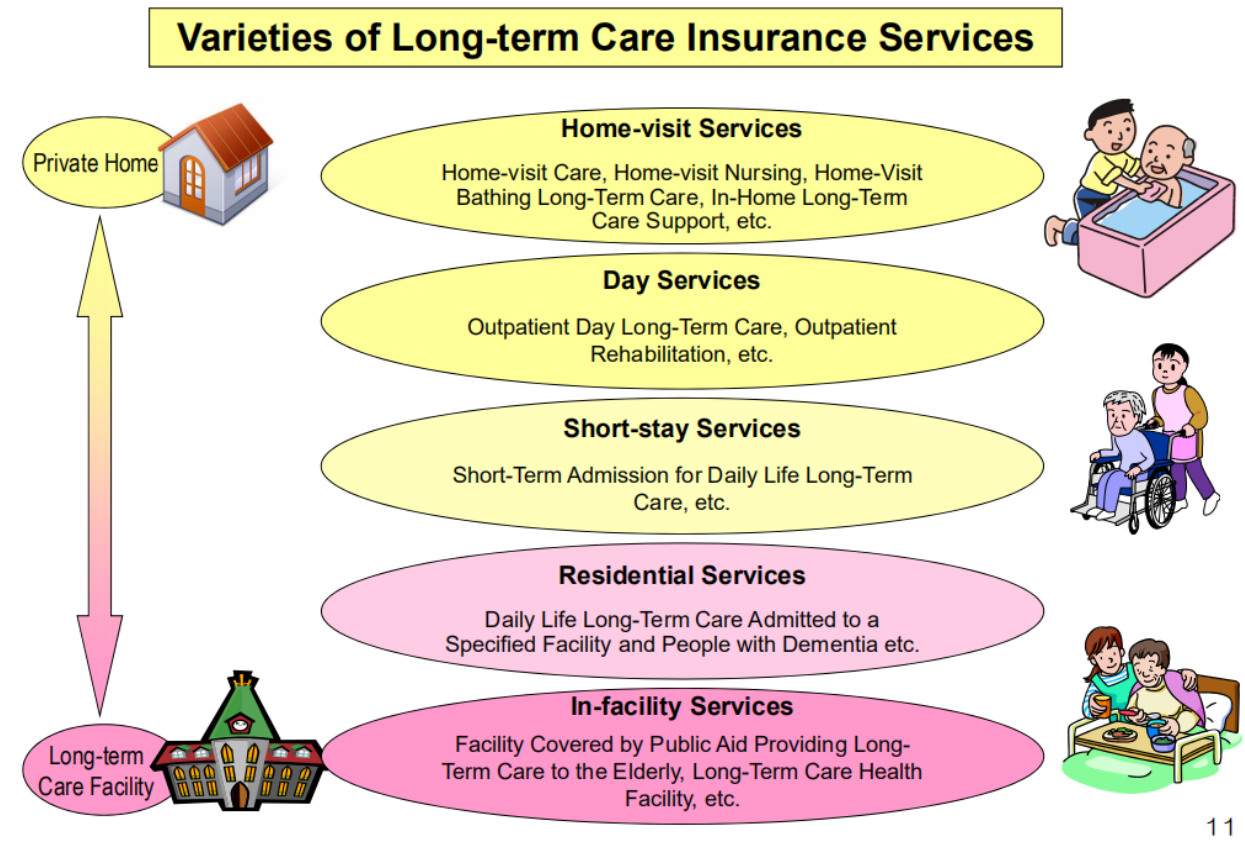

Fig. 2. Varieties of Long-term Care Insurance Services.

After the evaluation, the investigator will classify the insured into 7 levels, namely 'support Level 1', 'care Level 1', 'care Level 2', 'care Level 3', 'care Level 4', 'care Level 5' and 'self-reliant'. Responding to different levels of nursing requirements, long-term care services will be provided to qualified in the insured for 'care level'. Long-term care plans will be generated accordingly, providing special nursing homes, long-term home visits and other services; for those classified into 'support level', a range of preventive long-term care services will be provided; if rated as 'self-reliant', insured can enjoy community support level services. However, after several years of practice, the number of people in need of nursery in Japan continued to grow, premiums continued to rise, and the demand for professional nursing staff expanded. The defect of disproportionate focus on caring against disease-prevention comes clear. The demand for advanced nursery shrinks and more people need light care services and support services. In 2006, the Japanese government revised the long-term Nursing Insurance Law. Considering the growing number of nursery applicants, this revision will make disease prevention a top priority, encouraging the nationals to pay attention to prevention, trying not to use nursing insurance services and receiving nursing insurance services. At the same time, in response to the surge in demand for light care and assistance, the government changed the original seven major nursing insurance levels to eight levels, adding 'support Level 2' by combining prevention and treatment and attaching more importance to prevention. In response to the problem of rising premiums in successive years, the classification criteria have become more stringent. Some of the insured who originally belonged to the 'care level' have fallen to the 'support level' under the new classification criteria. The services enjoyed by insured in different levels are also limited. If the insured person is deemed to be in 'support level', he or she cannot be accommodated in a welfare facility or a convalescent medical facility to enjoy the 'care level' service. As a result, advanced and high-input services are compressed and saved, and the large expenditure of premiums can shrink to some extent. This stringent grading greatly reduces the possibility of misjudging the physical condition and provides the insured with the most accurate and appropriate care. Combined with the content of the service mentioned above, the professionalism and pertinence of nursing have been greatly improved. 


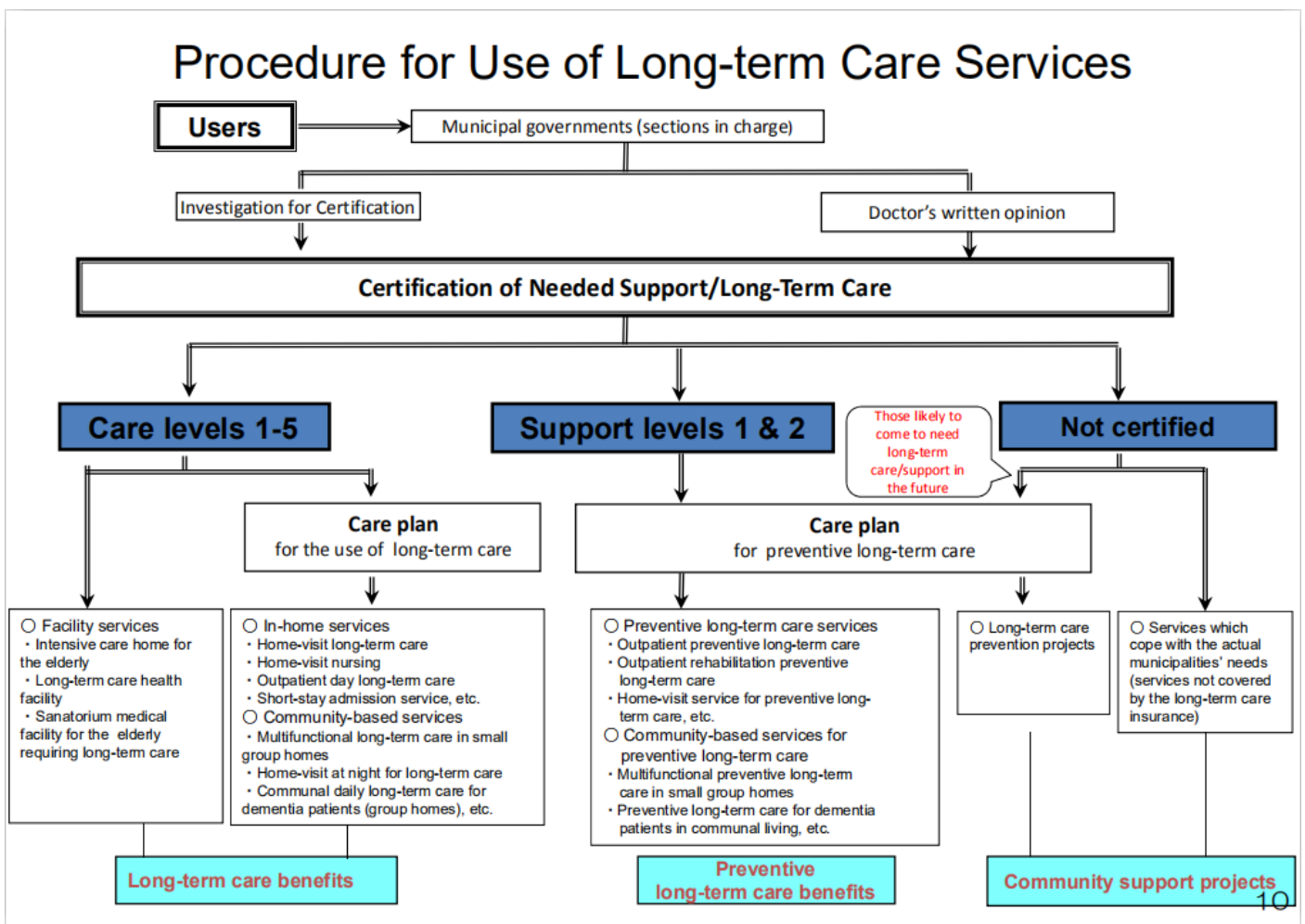

Fig. 3. Procedure for Long-term Care Services.

\section{F. Service Provision}

In terms of service provision, unlike the former pension scheme where the government alone took charge of designing and providing service, the new long-term care insurance system introduced in market entities, allowing various companies into the competition, which not only improves the quality of service, but also endows the insured freedom to choose the service they prefer.

\section{CONCLUSION}

The implementation of the long-term care insurance system has largely alleviated the social problems of Japan's rapid aging. According to statistics, the number of insurants aging 65 and more had increased by 1.53 times, from 21.65 million to 33.08 million, with the number of receivers of nursing service rising by 3.43 times, from 1.49 million to 5.11 million. This system covers the scope ranging from the range of the insured, financing methods, administrative mode, service content, and operational process to service provision. Its meticulous design greatly enhances the feasibility of its implementation. And it also remedied the early situation, making it possible for a senior citizen to receive easy and accessible one-stop service. At the same time, the system remains to be conducted in the unit of municipality, yet with refined management and service as well as enrichment of content. These reforms and improvements show the Japaneses government's keen attention to the functions of local administrations in handling the elderly-care issue, and thereby a shift of social welfare system from central government domination to joint participation and support of both central and local governments. Hence, the entity in charge of designing, deploying and implementing as well as the supporting facilities all get optimized, and a model for home-based care is established, setting foundation for the systematic operation and promotion of Japanese home-based care business.

\section{REFERENCES}

[1] World Bank Data Service (2019). Retrieved October, 17, 2019 from https://data.worldbank.org/indicator/SP.DYN.TFRT.IN?locations=JP

[2] Ministry of Health, Labour and Welfare(2019). Retrieved October 17 , 2019 from https://www.mhlw.go.jp/english/policy/care-welfare/carewelfare-elderly/index.html

[3] H. Yin, "New social security system-nursing insurance system in Japan," in Population Journal[J], 2000. No 2.2000, pp. 24-28. (in Chinese) 